\title{
Histopathological Findings of Endometrial Curettage Specimens in Women Having Abnormal Uterine Bleeding
}

Dr. Manjani. $\mathrm{S}^{1^{*}}$, Dr. Madhumittha. $\mathrm{R}^{1}$, Dr. Chitra. $\mathrm{T}^{2}$, Dr. Harke. A.B ${ }^{2}$, Dr. Viswanathan. $\mathrm{P}^{2}$, Dr. Saravanan. $\mathrm{E}^{2}$, Dr. Karthik. $\mathrm{S}^{3}$, Dr. Shobana. $\mathrm{B}^{1}$, Dr. Srismitha. $\mathrm{S}^{1}$

${ }^{1}$ Assistant Professor, Department of Pathology, Karpaga Vinayaga Institute of Medical Science and Research Center, P.O, GST Road, Chinna Kolambakkam, Palayanoor, Maduranthakam, Tamil Nadu 603308, India

${ }^{2}$ Professor, Department of Pathology, Karpaga Vinayaga Institute of Medical Science and Research Center, P.O, GST Road, Chinna Kolambakkam, Palayanoor, Maduranthakam, Tamil Nadu 603308, India

${ }^{3}$ Associate professor, Department of Pathology, Karpaga Vinayaga Institute of Medical Science and Research Center, P.O, GST Road, Chinna Kolambakkam, Palayanoor, Maduranthakam, Tamil Nadu 603308, India

DOI: $\underline{10.36348 / \text { sjpm.2021.v06i01.004 }}$

| Received: 26.12.2020 | Accepted: 03.01.2021 | Published: 09.01.2021

*Corresponding author: Manjani S

\section{Abstract}

Introduction: Abnormal uterine bleeding can manifest in various ways and is one of the common reasons for visit to the gynaecology OPD. Finding out the etiology is of paramount importance in the management of abnormal uterine bleeding. Histopathological study of endometrial curettings is one of the key ways to diagnose the cause of abnormal uterine bleeding. Materials and Methods: Study was conducted as a prospective study spanning over 2 year in the pathology Department of KIMS. The study participants include women with abnormal uterine bleeding who are subjected to general physical examination and basic laboratory investigations. Curettage specimens from these patients were subjected to histopathological examination to find out the etiology. Results: Examination was done on curettage specimens of 150 women presenting with abnormal uterine bleeding. The functional causes are more common than organic causes and the proportion increases as the age advances. Hyperplasias either simple, complex or atypical are more common organic etiologies. Endometrial adenocarcinoma is the most common malignancy encountered in the endometrial specimens. Conclusion: There are numerous functional and organic causes that can manifest as abnormal different bleeding. Diagnosis of these causes relies mainly on the histopathological examination of the curettage specimens. Hence management of abnormal uterine bleeding causes depends upon the histopathological diagnosis.

Keywords: Abnormal uterine bleeding (AUB), hyperplasia, menorrhagia, curettage, adenocarcinoma, proliferative, secretory.

Copyright $\odot 2021$ The Author(s): This is an open-access article distributed under the terms of the Creative Commons Attribution 4.0 International License (CC BY-NC 4.0) which permits unrestricted use, distribution, and reproduction in any medium for non-commercial use provided the original author and source are credited.

\section{INTRODUCTION}

AUB (Abnormal Uterine Bleeding) is one of the common reasons for visit to the gynaecologist. AUB is vaginal bleeding that is excessive, prolonged or occurring irregularly and infrequently. AUB accounts for about $30 \%$ of visits to the gynecologic OPD. It can manifest either as menorrhagia (excessive bleeding at regular intervals), polymenorrhea (normal bleeding at frequent intervals), polymenorrhagia (frequent, excessive bleeding), metrorrhagia (cyclical bleeding occurring irregularly or continuously between cycles) or menometrorrhagia (prolonged and irregular bleeding).

AUB is the term that encompasses both organic and non-organic causes of bleeding. Dysfunctional Uterine Bleeding (DUB) includes all forms of abnormal bleeding for which an organic cause cannot be found. It occurs commonly at the extremes of the reproductive age $(20 \%$ occur in adolescence and $40 \%$ occur in women over age 40 ).

\section{AIMS AND OBJECTIVES}

Endometrial curettings of women with AUB were studied histopathologically for organic and nonorganic etiologies in this study.

\section{MATERIALS AND METHODS}

The study spanned over a 2 year period from 2016 to 2018. It was conducted by the Pathology department of KVIMS (Karpaga Vinayaga Institute of Medical Sciences), Kanchipuram. Approval from the Institutional Ethical Committee was obtained. Informed consent was obtained from all individual participants included in the study. Endometrial samples were 
Manjani S et al; Saudi J Pathol Microbiol, Jan, 2021; 6(1): 13-18

obtained by dilatation and curettage from 150 women presenting with AUB during the aforementioned period.

Patients were subjected to general physical examination after obtaining complete history including medication use. This was followed by baseline investigations comprising of Complete blood count, bleeding and clotting time, chest radiograph and USG abdomen and pelvis.

We excluded women with systemic disorders, in situ contraceptive devices, hemostatic disorders, inadequate history, insufficient samples, pregnancy related disorders and antiplatelet therapy from the study.

All procedures performed in the current study were approved by IRB and/or national research ethics committee (reference number and date) in accordance with the 1964 Helsinki declaration and its later amendments.

\section{RESULTS}

Curettage specimens of one hundred and fifty women with AUB were subjected to histopathological examination. The age of the patients studied were categorized into three groups namely reproductive, perimenopausal and post-menopausal. Patients with AUB ranged from 23 to 65 years with a mean age of 42.6 years and a median age of 42 years. The age distribution of patients presenting with AUB is shown in Table- 1 .
Of these 150 patients, $63.3 \%$ of patients are of low parity ( $\mathrm{P} 1$ or $\mathrm{P} 2), 36 \%$ of patients were multiparous and only one patient $(0.7 \%)$ was nulliparous. The most common complaint was menorrhagia $(58.7 \%)$, followed by metrorrhagia (23.3\%). Meno-metrorrhagia constituted $12 \%$ and postmenopausal bleeding is seen in $8.7 \%$ of patients. Polymenorrhea was rare, seen in 2 $(1.3 \%)$ patients. It can be noted that in women aged 18 to $50 \mathrm{yrs}$, menorrhagia is the predominant manifestation of AUB followed by metrorrhagia.

Histopathological examination can distinguish between organic and functional etiologies. In overall, functional etiologies are slightly more common than organic etiologies. But it should be noted that as the age advances, the proportion of functional causes increase (49\% in $18-40 \mathrm{yrs}, 55 \%$ in $41-50 \mathrm{yrs}$ and $61 \%$ in $>50$ yrs).

In the reproductive age group, the commonest histopathological diagnosis was simple hyperplasia $(28.6 \%)$, followed by proliferative pattern (22.2\%), secretory pattern $(15.9 \%)$ complex hyperplasia $(9.5 \%)$ and disordered proliferative endometrium $(6.3 \%)$. Whereas, proliferative pattern was commonly seen in the perimenopausal age group followed by simple and complex hyperplasia and secretory pattern.

The commonest histopathological diagnosis in patients presenting with post-menopausal bleeding was atrophic endometrium $(53.8 \%)$ followed by simple hyperplasia $(15.4 \%)$, disordered proliferative endometrium (7.7\%), endometrial adenocarcinoma $(7.7 \%)$, atypical hyperplasia $(7.7 \%)$ and squamous cell carcinoma infiltrating endometrium $(7.7 \%)$.

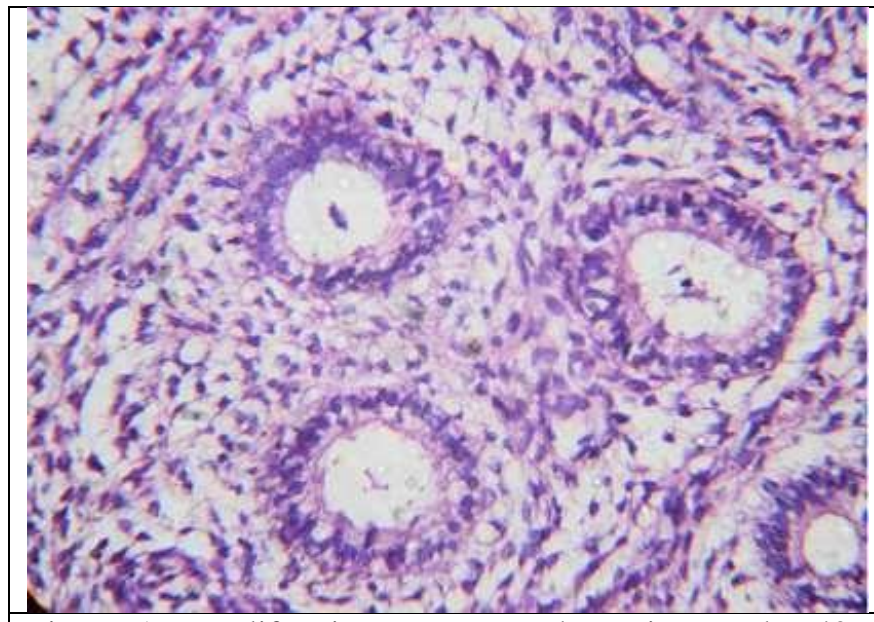

Picture-1: Proliferative Pattern photomicrograph 40x magnification showing widely spaced tubular glands, pseudostratification and mitosis

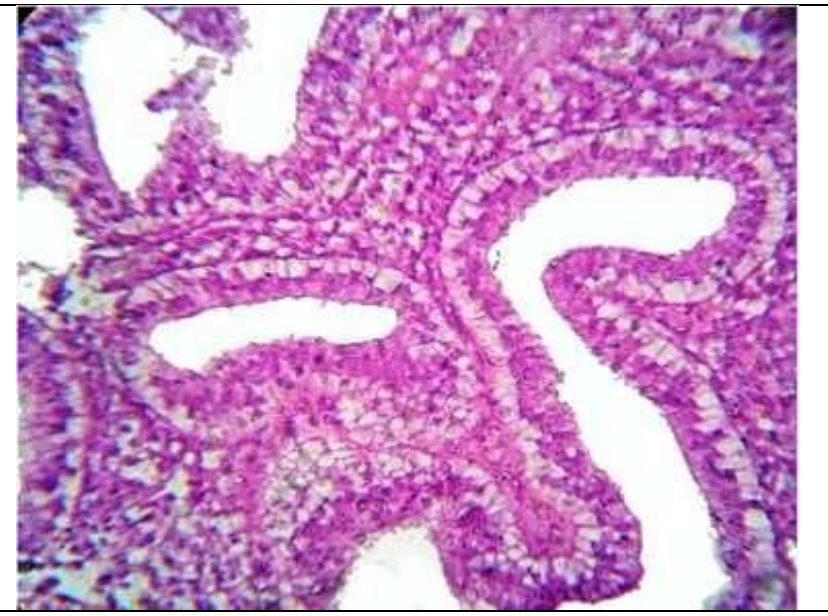

Picture-2: Secretory phase-photomicrograph under 40x showing tubular glands with subnuclear vacuolation 


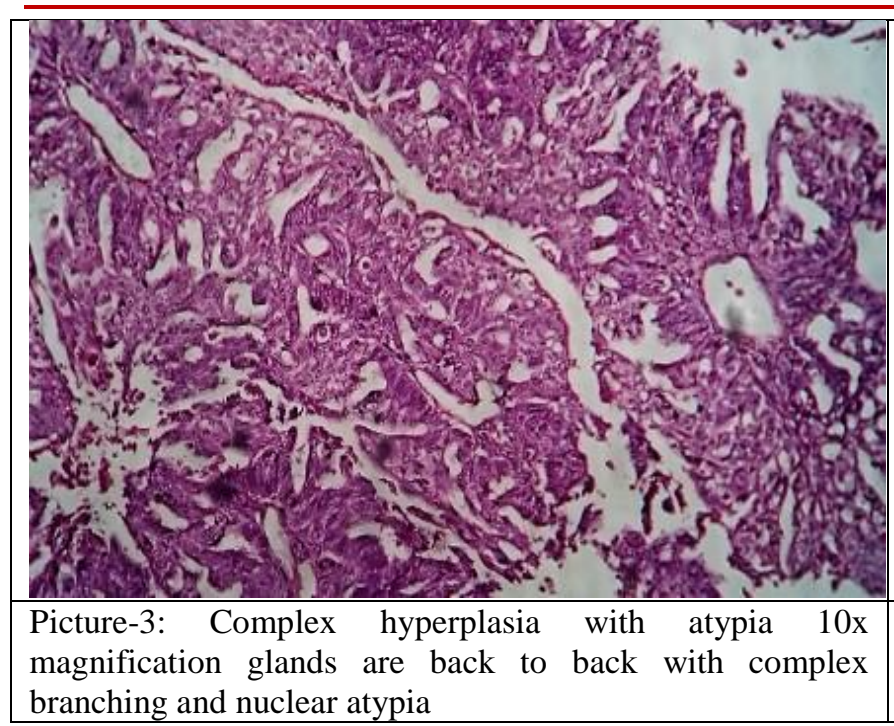

The functional causes of AUB in all women studied include proliferative pattern, secretory pattern, disordered proliferative endometrium, atrophic endometrium, menstrual phase, hormonal changes, irregular shedding, and mixed pattern in declining order of frequency.

The organic etiologies as demonstrated by HPE (Histopathological) examination of curretings in women with AUB is shown in the Table-3 below.

Simple hyperplasia (56.3\%) was the commonest organic cause in the reproductive age group followed by complex hyperplasia (18.8\%), endometrial polyps $(9.4 \%)$, secretory hyperplasia $(6.3 \%)$, atypical hyperplasia (6.3\%) and Arias stella effect (3.1\%). Similarly, in women aged 41-50 yrs, the commonest organic etiologies include simple hyperplasia, complex hyperplasia, polyps, secretory hyperplasia, endometrial adenocarcinoma, atypical hyperplasia, chronic endometritis, endometrial metaplasia and granulomatous TB in decreasing order of frequency. Whereas in the post-menopausal age group, there were two cases of simple hyperplasia and one case each in

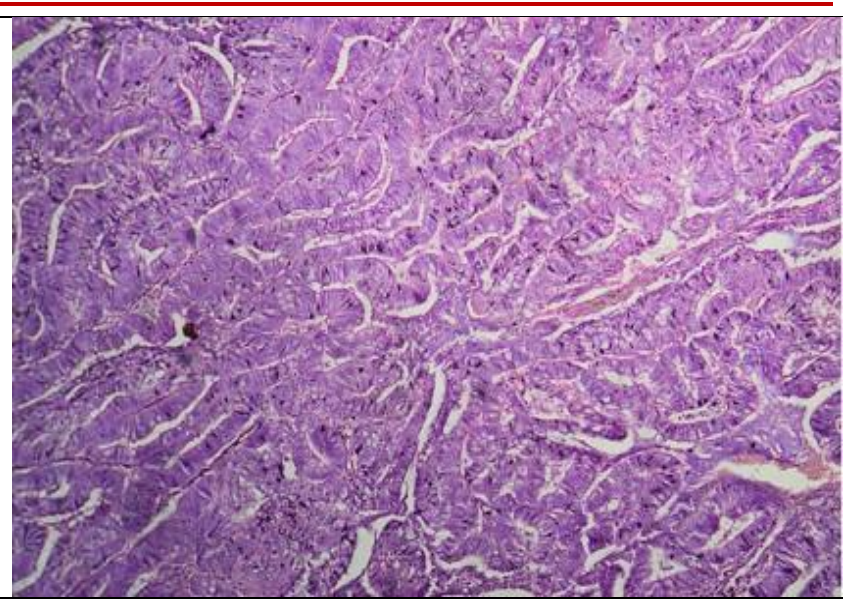

Picture-4: Adenocarcinoma-40x magnification complex branching forming labyrinthine pattern with no intervening stroma

endometrial adenocarcinoma, atypical hyperplasia and squamous cell carcinoma infiltrating endometrium.

The histopathological patterns of women with menorrhagia in declining order of frequency are proliferative pattern, secretory pattern, simple hyperplasia, complex hyperplasia, disordered proliferative endometrium, endometrial polyp, menstrual phase endometrium and so on. Likewise, the histological findings in patients presenting with metrorrhagia are simple hyperplasia (31.4\%), proliferative pattern $(14.3 \%)$, secretory pattern $(14.3 \%)$, complex hyperplasia $(11.4 \%)$, disordered proliferative endometrium $(5.7 \%)$, secretory hyperplasia $(5.7 \%)$, endometrial adenocarcinoma $(5.7 \%)$ and so on. In abnormal uterine bleeding due to both organic and nonorganic causes, menorrhagia was the commonest pattern of bleeding seen followed by metrorrhagia.

Table-1: Age group of patients presenting with AUB

\begin{tabular}{|l|l|l|}
\hline Age group (years) & Total & $\%$ \\
\hline 18 - 40 years (reproductive) & 63 & 42 \\
\hline $41-50$ years (perimenopausal) & 74 & 49 \\
\hline$>50$ years (postmenopausal) & 13 & 9 \\
\hline Total & 150 & 100 \\
\hline
\end{tabular}

Table-2: Abnormal uterine bleeding due to Organic causes

\begin{tabular}{|l|l|l|l|}
\hline S.№ & HISTOPATHOLOGICAL DIAGNOSIS & Total & \% \\
\hline 1 & Simple hyperplasia & 32 & 45.71 \\
\hline 2 & Complex hyperplasia & 14 & 20.00 \\
\hline 3 & Endometrial polyp & 6 & 8.57 \\
\hline 4 & Atypical hyperplasia & 5 & 7.14 \\
\hline 5 & Secretory hyperplasia & 4 & 5.71 \\
\hline 6 & Endometrial adenocarcinoma & 3 & 4.29 \\
\hline 7 & Chronic endometritis & 2 & 2.86 \\
\hline 8 & Arias stella effect & 1 & 1.43 \\
\hline 9 & Endometrial metaplasia & 1 & 1.43 \\
\hline 10 & Granulomatous TB & 1 & 1.43 \\
\hline 11 & Squamous cell carcinoma infiltrating endometrium & 1 & 1.43 \\
\hline & Total & 70 & 100.00 \\
\hline
\end{tabular}


Manjani S et al; Saudi J Pathol Microbiol, Jan, 2021; 6(1): 13-18

Table-3: Frequency of Different Histopathological Patterns of Endometrial Specimens in Abnormal Uterine Bleeding in all age groups

\begin{tabular}{|l|l|l|l|l|l|l|}
\hline S.No & TOPATHOLOGICAL DIAGNOSIS & Age group ( years) & \multirow{2}{*}{ Total } & \multirow{2}{*}{} \\
\cline { 3 - 6 } & & $\mathbf{1 8} \mathbf{- 4 0}$ & $\mathbf{4 1} \mathbf{- 5 0}$ & $\mathbf{5 0}$ & \\
\hline 1 & Simple hyperplasia & $18(28.6 \%)$ & $12(16.2 \%)$ & $2(15.4 \%)$ & 32 & 21.33 \\
\hline 2 & Proliferative pattern & $14(22.2 \%)$ & $17(23 \%)$ & 0 & 31 & 20.67 \\
\hline 3 & Secretory pattern & $10(15.9 \%)$ & $11(14.9 \%)$ & 0 & 21 & 14 \\
\hline 4 & Complex hyperplasia & $6(9.5 \%)$ & $8(10.8 \%)$ & 0 & 14 & 9.33 \\
\hline 5 & Disordered proliferative endometrium & $4(6.3 \%)$ & $5(6.8 \%)$ & $1(7.7 \%)$ & 10 & 6.67 \\
\hline 6 & Atrophic endometrium & 0 & $2(2.7 \%)$ & $7(53.8 \%)$ & 9 & 6 \\
\hline 7 & Endometrial polyp & $3(4.8 \%)$ & $3(4.1 \%)$ & 0 & 6 & 4 \\
\hline 8 & Menstrual phase & $3(4.8 \%)$ & $3(4.1 \%)$ & 0 & 6 & 4 \\
\hline 9 & Atypical hyperplasia & $2(3.2 \%)$ & $2(2.7 \%)$ & $1(7.7 \%)$ & 5 & 3.33 \\
\hline 10 & Secretory hyperplasia & $2(3.2 \%)$ & $2(2.7 \%)$ & 0 & 4 & 2.67 \\
\hline 11 & Endometrial adenocarcinoma & 0 & $2(2.7 \%)$ & $1(7.7 \%)$ & 3 & 2 \\
\hline 12 & Chronic endometritis & 0 & $2(2.7 \%)$ & 0 & 2 & 1.33 \\
\hline 13 & Arias stella effect & $1(1.6 \%)$ & 0 & 0 & 1 & 0.67 \\
\hline 14 & Endometrial metaplasia & 0 & $1(1.4 \%)$ & 0 & 1 & 0.67 \\
\hline 15 & Granulomatous TB & 0 & $1(1.4 \%)$ & 0 & 1 & 0.67 \\
\hline 16 & Hormonal changes & 0 & $1(1.4 \%)$ & 0 & 1 & 0.67 \\
\hline 17 & Irregular shedding & 0 & $1(1.4 \%)$ & 0 & 1 & 0.67 \\
\hline 18 & Mixed pattern & 0 & $1(1.4 \%)$ & 0 & 1 & 0.67 \\
\hline 19 & Squamous cell carcinoma infiltrating endometrium & 0 & 0 & 1 & 1 & 0.67 \\
\hline & Total & $63(100 \%)$ & $74(100 \%)$ & $13(100 \%)$ & 150 & 100 \\
\hline
\end{tabular}

Table-4: Different types of endometrial hyperplasia

\begin{tabular}{|l|l|l|l|}
\hline S.№ & Type & № of cases & \% \\
\hline 1 & Simple hyperplasia & 32 & 62.7 \\
\hline 2 & Complex hyperplasia & 14 & 27.5 \\
\hline 3 & Atypical hyperplasia & 5 & 9.8 \\
\hline & Total & 51 & 100 \\
\hline
\end{tabular}

Table-5: Incidence of Common Organic Etiologies of Abnormal Uterine Bleeding (\%)

\begin{tabular}{|l|l|l|l|l|l|l|}
\hline $\begin{array}{l}\text { S. } \\
\text { № }\end{array}$ & Study & $\begin{array}{l}\text { Hyperplasia } \\
\text { (number of cases) }\end{array}$ & $\begin{array}{l}\text { Pregnancy } \\
\text { complications }\end{array}$ & Endometritis & Polyp & Malignancy \\
\hline 1. & Present study & $33(51)$ & Excluded & 1.33 & 4 & 2 \\
\hline 2. & Soleymani E [1] & $2.5(15)$ & - & - & 3.9 & 0.7 \\
\hline 3. & Mariam abid [6] & $5(12)$ & Excluded & 12 & 14 & 2 \\
\hline 4. & Doraiswami saraswathi [7] & $6.11(25)$ & 22.74 & 4.15 & 11.24 & 4.4 \\
\hline 5. & Bhatta S [5] & $18.03(22)$ & Excluded & 6.56 & 2.46 & 5.74 \\
\hline 6. & Sujatha Jetley [4] & $10.9(24)$ & 1.3 & 9.1 & 2.7 & 0 \\
\hline 7. & Ifeyinwa Mary Asuzu [10] & $10(49)$ & 62.6 & 1.43 & 9.9 & 0.41 \\
\hline 8. & Navjot Kaur [2] & $21(21)$ & Excluded & 6.5 & 0 & 9.5 \\
\hline 9. & Rehana Khan [3] & $20.5(21)$ & Excluded & 12.7 & 3.9 & 0 \\
\hline
\end{tabular}

Among women of all age groups, simple hyperplasia was the most frequent type of hyperplasia followed by complex and atypical hyperplasia.

Correlation between endometrial thickness and histological pattern revealed that most cases of hyperplasia have endometrial thickness between 5 and $15 \mathrm{~mm}$ (with 3 case having thickness > $15 \mathrm{~mm}$ ), whereas all cases of atrophic endometrium have endometrial thickness $<10 \mathrm{~mm}$. Thus the histological diagnosis correlated well with the ultrasound findings.

\section{DISCUSSION}

AUB was more common in the perimenopausal women followed by women in the reproductive age.Studies including Soleymani E et al., [1] reported a similar finding.

Menorrhagia $(58.7 \%)$ was the most common symptom followed by metrorrhagia $(23.3 \%)$. Navjot Kaur [2], Rehana Khan [3] and Sujatha Jetley [4] also noted menorrhagia as the commonest symptom. Metrorrhagia is the commonest complaint in studies like Bhatta S [5]. Polymenorrhea is a rare complaint in 
Manjani S et al; Saudi J Pathol Microbiol, Jan, 2021; 6(1): 13-18

our study, whereas it is the commonest complaint in Mariam abid [6].

AUB can be either functional or organic. In our study, functional etiologies account for slightly more $(53 \%)$ than organic etiologies. Other studies like Doraiswami saraswathi [7], Navjot kaur [2], Sujatha Jetley [4] and Sirichoke [8] revealed similar findings. In few studies like Mariam abid [6], organic causes are more common than functional cuases.

Among the functional patterns, proliferative and secretory patterns were noted at histology as seen in most studies. In the present study, these patterns account for one third of the causes. Highest incidence of cyclical patterns was observed by Soleymani E [1] (81.4\% of cases)

In our study, Disordered proliferative endometrium accounted for about $7 \%$ of cases. Maximum incidence of this finding $(20.53 \%)$ is seen in Doraiswami saraswathi [7]. It is also a common cause of DUB in Soleymani E [1], where it accounts for $15.3 \%$ cases.

Atrophic endometrium is rarely seen in women of reproductive age group. It is seen sometimes in perimenopausal women, but it is a common finding in post-menopausal women due to lack of ovarian estrogen. Its incidence in the present study is $6 \%$, which is almost similar to that obsereved by Mariam abid [6]. Atrophic endometrium was most commonly noted in women aged over 50 than in perimenopausal women. About one third of AUB was due to hyperplasia in this study. Hyperplasia ranked second only to normal cyclical patterns as the cause of AUB in most of the studies. In the present study also hyperplasia is the second common cause of AUB.

The older terminologies like cystoglandular hyperplasia and adenomatous hyperplasia were used in some of the studies. These were replaced my newer terminologies like simple, complex and atypical hyperplasia in recent studies. Comparative analysis of the incidence of organic causes of AUB in various studies show that hyperplasias is the commonest organic cause of AUB. In contrast studies like Mariam abid [6], Soleymani E [1] and Sirichoke [8] reported lower incidence of hyperplasia. Moderate to heavy vaginal bleeding is seen in women with hyperplasia, whereas women with atrophic endometrium may have only spotting.

Among all the hyperplasias, 5-10\% progressed to malignancy. Progression to malignancy was noted in $1 \%$ of simple hyperplasia, $3 \%$ of complex hyperplasia, $8 \%$ of simple hyperplasia with atypia and $29 \%$ of complex hyperplasia with atypia [9]
It is observed that in some studies like Doraiswami saraswathi [7] and Ifeyinwa [10], pregnancy complication was a common cause of AUB. However in our study pregnancy related disorders were excluded. Moreover in a study done by Ifeyinwa [10] pregnancy complications was the commonest cause of AUB. Hence, this cause should be kept in mind when evaluating AUB in women of reproductive age group. These patients should be investigated with urine gavindex test for pregnancy [11].

Endometritis accounted for $<2 \%$ of AUB in the present study. Bhatta S [5] (6.56\%), Rehana Khan [3] $(12.7 \%)$ and Sujatha [4] $(9.1 \%)$ reported endometritis as a significant cause of AUB. In the present study one case of tuberculous endometritis was noted. Doraiswami saraswathi [7] and Bhatta S [5] each reported one case of tuberculous endometritis.

Polyps were seen in $4 \%$ of AUB cases in our study. The highest incidence of these polyps was seen in Mariam abid [6] (14\%) and Sirichoke [8] (15.3\%). It can also be inferred from these studies that the incidence of polyps increase as age advances. In fact, polyps was the most common pathology in postmenopausal women in Mariam abid [6]. Doraiswami saraswathi [7] also reported a high incidence of polyps (11.24\%). They found that most of the polyps were seen in women aged 41-50 yrs. However, there is no greater propensity of polpys undergoing malignant change when compared with the adjacent normal endometrium [12].

AUB due to malignancy was less common but important cause. In the present study, 3 cases of endometrial carcinoma were seen. Two cases were seen in 41- $50 \mathrm{yrs}$ and one malignancy was seen in women over age 50. In most of the studies, endometrial carcinoma was the commonest histological subtype. Rare malignancies like malignant mixed mullerian tumor (MMMT), endometrial stromal sarcoma and adenosarcoma were noted in some studies.

Navjot Kaur [2], Bhatta S [5] and Doraiswami saraswathi [7] reported a high incidence of malignancies at $9.5 \%, 5.74 \%$ and $4.4 \%$ respectively. In Doraiswami saraswathi [7], one out of 18 cases of malignancy was malignant mixed mullerian tumor. The remaining were endometrial carcinoma. Patients with MMMT are usually postmenopausal and commonly present with AUB. Risk factors of endometrial carcinoma include nulliparity, obesity and chronic anovulation.

\section{CONCLUSION}

It can be concluded from the study that though there are numerous causes of AUB, hyperplasias (simple and complex with or without atypia) and the functional patterns (proliferative and secretory patterns) are the predominant etiologies. Malignancy, although 
Manjani S et al; Saudi J Pathol Microbiol, Jan, 2021; 6(1): 13-18

less common is an important cause. Hence curettage and histopathological examnination should be done in all women presenting with AUB (after excluding pregnancy related disorders) to rule out malignancy and its precursors (including atypical hyperplasia).

\section{REFERENCES}

1. Soleymani, E., Ziari, K., Rahmani, O., Dadpay, M., Taheri-Dolatabadi, M., Alizadeh, K., \& Ghanbarzadeh, N. (2014). Histopathological findings of endometrial specimens in abnormal uterine bleeding. Archives of gynecology and obstetrics, 289(4), 845-849.

2. Kaur, N., Chahal, J. S., Bandlish, U., Kaul, R., Mardi, K., \& Kaur, H. (2014). Correlation between cytological and histopathological examination of the endometrium in abnormal uterine bleeding. Journal of Cytology/Indian Academy of Cytologists, 31(3), 144-148.

3. Khan, R., Sherwani, R. K., Rana, S., Hakim, S., \& Jairajpuri, Z. S. (2016). Clinco-pathological patterns in women with dysfunctional uterine bleeding. Iranian journal of pathology, 11(1), 2026.

4. Jetley, S., Rana, S., \& Jairajpuri, Z. S. (2013). Morphological spectrum of endometrial pathology in middle-aged women with atypical uterine bleeding: A study of 219 cases. Journal of mid-life health, 4(4), 216-220.

5. Bhatta, S., \& Sinha, A. K. (2012). Histopathological study of endometrium in abnormal uterine bleeding. Journal of pathology of nepal, 2(4), 297-300.

6. Abid, M., Hashmi, A. A., Malik, B., Haroon, S.,
Faridi, N., Edhi, M. M., \& Khan, M. (2014). Clinical pattern and spectrum of endometrial pathologies in patients with abnormal uterine bleeding in Pakistan: need to adopt a more conservative approach to treatment. $B M C$ Women's Health, 14(1), 1-7.

7. Doraiswami, S., Johnson, T., Rao, S., Rajkumar, A., Vijayaraghavan, J., \& Panicker, V. K. (2011). Study of endometrial pathology in abnormal uterine bleeding. The journal of Obstetrics and Gynecology of India, 61(4), 426-430.

8. Tumrongkunagon, S., \& Suknikhom, W. (2019). Histological Sampling of Endometrial Tissue: Comparison between the MedGyn ${ }^{\circledR}$ Endosampler and Formal Fractional Curettage in Patients with Abnormal Uterine Bleeding. Asian Pacific journal of cancer prevention: APJCP, 20(11), 3527.

9. Kurman, R. J., Kaminski, P. F., \& Norris, H. J. (1985). The behavior of endometrial hyperplasia. A long- term study of "untreated" hyperplasia in 170 patients. Cancer, 56(2), 403-412.

10. Asuzu, I. M., \& Olaofe, O. O. (2018). Histological Pattern of Endometrial Biopsies in Women with Abnormal Uterine Bleeding in a Hospital in North Central Nigeria. International Journal of Reproductive Medicine, 2018.

11. Kilbourn, C. L., \& Richards, C. S. (2001). Abnormal uterine bleeding: diagnostic considerations, management options. Postgraduate medicine, 109(1), 137-150.

12. McCluggage, W. G. (2011). Benign Diseases of the Endometrium. In Kurman, R. J ELRe. Blaustein's Pathology of the Female Genital Tract. 6th ed. New York: Springer. 305-358. 